\title{
Política y corrupción.
}

Nuevo capítulo de la batalla cultural

\author{
Carlos Raimundi \\ Ethel Galarza
}

\section{Presentación}

Una falacia principal en la que nos ha hecho caer el largo proceso de colonización cultural conducido por el poder real, ha sido que el grueso de la sociedad crea y convalide que sólo el universo de la llamada "política" es quien hace política. En este sentido, es necesario diferenciar entre Política como dispositivo militante independiente de intereses privados y Política como capacidad de incidir.

En términos de capacidad de influencia, la actividad privada suele tener más poder político que la propia actividad política independiente. Pensemos, por ejemplo, en grupos trasnacionales como Unilever, Procter \& Gamble, Johnson \& Johnson, que proveen el $90 \%$ de nuestros productos de uso cotidiano, y su capacidad de influir en el proceso de abastecimiento/ desabastecimiento, como el que padece en estos momentos el pueblo y el gobierno popular de Venezuela.

Pensemos, asimismo, en un contexto de restricción externa, esto es, disponibilidad limitada de divisas para el funcionamiento de una economía dependiente, como la nuestra. En este caso, un grupo oligopólico de exportadoras de granos, que, en carácter de tal, puede manejar especulativamente el mercado de divisas, tiene más capacidad de incidir -y extorsionar- que el propio Estado.

Estos grupos tienen capacidad económica para realizar sus propios seminarios, simposios nacionales e internacionales, crear ONGs y fundaciones, tener medios de comunicación, universidades, publicaciones, etc. Y no tienen que rendir cuentas 
de los gastos que ello demanda, porque, supuestamente, se trata de "dinero privado" ("con mi plata hago lo que quiero", con "la plata de todos", no se puede hacer lo que se quiere). En este marco, cabría preguntarse ¿cómo hace la política independiente para financiar estas mismas actividades, de modo de divulgar una concepción distinta de cómo organizar la sociedad?

Estamos, pues, frente a un dilema: cuando la política independiente toma el control del Estado, en el terreno de disputa política están el Estado -representado por la política independiente- y las corporaciones. Pero cuando las corporaciones toman el control del Estado, como en estos momentos, están sólo ellas. ¿Quién las interpela entonces, si ellas dominan el campo privado y también el universo de lo público?

\section{La falsedad de asociar corrupción y política. Causas de nuestro apego a la ilegalidad como sociedad}

Los poderes fácticos han entablado una larga "cruzada moralizadora" contra lo que pretenden sea la "corrupción generalizada" de la política, tema al que sólo apelan cuando ésta intenta poner límites a sus intereses, como sucedió durante los gobiernos kirchneristas. Nunca denunciaron la concentración no republicana de poder cuando la jefatura de los tres poderes constituidos era detentada por miembros de un mismo estudio jurídico de La Rioja: Carlos Menem (poder ejecutivo), Eduardo Menem (poder legislativo) y Julio Nazareno (poder judicial). Y no lo hicieron porque el menemismo respondía a sus intereses.

Según la experiencia argentina, hay algunos factores históricos que figuran como posibles fuentes de la corrupción, a la que los poderes fácticos centran en la política y el Estado, pero que está diseminada entre las prácticas de todos los campos de acción de nuestra sociedad, porque proviene de etapas fundacionales de nuestra institucionalidad muy arraigadas en nuestra cultura.

Entre esas fuentes principales de nuestras conductas ilegales está el desapego atávico a las instituciones, arrastrado desde el 
período colonial. Cuando las instituciones no responden, surge la justificación a tomar caminos no-institucionales. Otra de las fuentes de nuestra tendencia a actuar por fuera de la ley ha sido el quiebre de determinados pactos tácitos que operan como fundacionales de una sociedad. 1. El pacto tributario, es decir, comprometerse a pagar los impuestos porque el Estado se compromete a devolverlos en servicios de calidad (roto). 2. El pacto previsional, es decir, aportar parte de nuestro salario para recibir una jubilación digna (roto). 3. El pacto financiero, es decir, el dinero depositado es del depositante, no del banco (roto). 4. La convención sobre el valor de nuestra moneda, que se fue perdiendo estrepitosamente a través de los años (roto). Todas estas rupturas parten de gobiernos que defraudaron la voluntad popular mayoritaria, y se arrastran desde hace tantos años que, pese a la reparación de los doce años de gobierno kirchnerista, todavía anidan hondamente en la memoria colectiva. Entonces, continúa una tendencia a no sancionar nuestros comportamientos ilegales, que inundan en mayor o menor medida a toda nuestra sociedad, y por lo tanto también a los funcionarios. Pero, contrariamente a lo que los grandes medios pretenden instalar, no sólo a los funcionarios, sino a empresarios, comerciantes, profesionales, celebridades de la farándula, deportistas, etc.

\section{El "negocio" privado de denostar a la política}

Volviendo al tema inicial, el financiamiento legal de la política es insuficiente, y eso la impide a la política independiente solventar sus requerimientos económicos, de modo que pueda interpelar en igualdad de condiciones a los grandes conglomerados económico-financieros, que pretenden imponerle a la política sus propios intereses. Esto de ninguna manera significa justificar mecanismos ilegales de financiamiento politico, pero sí identificar un cuello de botella muy importante.

Es necesario incrementar notablemente las partidas legales del presupuesto destinadas al financiamiento de la política, pero es un debate público difícil de saldar favorablemente, por 
cuanto también está muy arraigado socialmente el desprestigio de la política. Las grandes cadenas hegemónicas de medios han perserverado en mostrar siempre las peores facetas de la política en cuanto militancia independiente, aunque esas peores facetas están presentes en toda actividad. De modo que la ciudadanía tome distancia de todo compromiso político, y deje así el terreno de las decisiones políticas a disposición de intereses minoritarios. Ahora bien, los grupos financieros, que, como queda dicho, son actores centrales de la política, disponen de mucho dinero y de recursos de todo tipo para incidir sobre lo que sucede, es decir, de hacer política.

Cuando un gobierno popular ocupa ese terreno y gobierna en defensa de los más humildes, necesariamente afecta los intereses de los grupos más privilegiados, los fastidia, y éstos arrecian su crítica y sus estrategias de desestabilización. Una de ellas, es la acusación sistemática a la política de ser corrupta. De esta manera la toman como rehén: a la menor señal de autonomía de la política respecto de las imposiciones de los poderes fácticos, éstos profundizan las técnicas para desgastarla.

\section{La capacidad del poder de establecer la percepción de lo legal y lo ilegal en el sentido común}

Una de las atribuciones del poder (a escala internacional podríamos traducirlo como "atribuciones del Imperio") es no sólo ejercer su supremacía económica, financiera, militar o tecnológica, sino fundamentalmente la cultural, esto es, influir en la formación del sentido común de una parte determinante de la sociedad. Francis Stonow Sanders, en "La CIA y la guerra fría cultural", habla de "las mentiras necesarias" y las "negaciones creíbles", de la propaganda y la conquista de las mentes, de distribuir información, ideas o doctrinas por diferentes medios para influir en el pensamiento de determinados grupos. "La propaganda más efectiva -dice la CIA- es aquella en que las personas se mueven en la dirección que nosotros queremos, pero piensan que lo hacen por sus propias ideas." Y esta hegemonía o 
dominación cultural consiste, entre otras cosas, en su capacidad para determinar los criterios o parámetros de legalidad; qué cosas son legales y cuáles son ilegales, siempre de acuerdo con sus propios intereses. Así, se presume ilegal la conducta expuesta en un video donde se cuentan algunos millones de dólares, pero no lo es el saqueo de miles de millones de dólares consumado con la derogación de la ley cerrojo para el canje de deuda, la ley de pago soberano apoyada por una abrumadora mayoría de países en el seno de las Naciones Unidas, o el vaciamiento del sistema previsional estatal para dejarlo a merced de la re-privatización.

\section{El papel asignado al "partido judicial"}

En los últimos tiempos, a la alianza de intereses entre las corporaciones financieras y los grandes medios de difusión, se ha sumado una parte del servicio de justicia, por eso los medios promocionan a ciertos jueces y fiscales como personas "probas e inmaculadas" (Griesa, juez Moro en Brasil, Lorenzetti, Bonadío, Nisman, en la Argentina) que serían, eventualmente, capaces de remplazar a "esos políticos corruptos". Si así fuera, serían mucho más manejables por parte de esas corporaciones.

El mundo judicial no sólo incluye a los magistrados, sino también a los profesionales privados, y está profundamente politizado. Todos sabemos que cuando se convoca a elecciones en los colegios de abogados o en los claustros universitarios, las listas están integradas y patrocinadas por espacios políticos. De allí la legitimidad del principio que inspiró la reforma judicial de 2014, malograda por la Corte Suprema de Justicia de la Nación, órgano eminentemente político y sobreabundantemente politizado. Si bien no hay condiciones para intervenir externamente en las elecciones profesionales, sí las hay para universalizar la elección de los miembros de las instituciones públicas del mundo judicial. No se trata de politizar un ámbito que ya está claramente politizado, sino de democratizar los alcances de esa politización.

Por otra parte, los propios poderes fácticos, en acuerdo con las cadenas hegemónicas de medios que dan soporte y se 
dedican a legitimar socialmente sus intereses, se han dedicado a que la sociedad sobrevalore el papel del poder judicial como garante de la calidad de la democracia, cuando, en realidad, algunos de sus rasgos centrales responden mucho más a los procesos monárquicos que a los democráticos. Valga como ejemplo su condición vitalicia -cuando no hereditaria-, su negativa a pagar determinados impuestos y su elección cerrada, corporativa y contra-mayoritaria.

\section{La equívoca distinción entre recursos públicos y privados. Los recursos corresponden a toda la organización social}

Mi inquietud para desentrañar la encerrona cultural que asocia a la corrupción con la política en el sistema de percepciones más generalizado, y exculpa a otras actividades, comenzó a partir del debate sobre el uso de la pauta publicitaria oficial. En primer lugar, ella ocupa un ínfimo volumen dentro de la publicidad total; hablamos de un 5\% frente a un 95\%. También en este rubro, los privados dicen que con la pauta privada tienen derecho de hacer lo que quieren, porque se trata de "su" dinero. Entonces, no sólo hacen lo que quieren con el 95\% de la pauta privada, sino que también buscan incidir en el destino de la pauta oficial, es decir, abordar a la vez lo privado y lo público. Se trata de una gran trampa cultura.

Además, recordemos que cuando el programa de más rating de la TV Pública, Fútbol para Todos, decidió poner el partido principal a competir con un programa del grupo Clarín, los defensores de este último saltaron diciendo que eso no correspondía. Sin embargo, cuando una emisora privada tiene un producto de mucho rating, lo ubica el día y en el horario que más le conviene, cuando piensa que más audiencia va a tener, $o$ bien cuando compite con otro producto de mucho rating. ¿Por qué la tv pública no podía hacer lo mismo? Otra trampa: cuando la tv pública no compite se la tilda de anticuada, aburrida o anacrónica, y cuando decide competir de igual a igual con lo privado también se la cuestiona. 
En definitiva, es cierto que el dinero de la pauta oficial "es de todos", porque proviene de impuestos. Pero el dinero de la pauta privada también "es de todos", porque proviene del consumo popular. Si las empresas tienen mucho dinero para publicitarse, ya sea en gráfica, en radio y tv o en internet, es porque hubo políticas públicas que incrementaron la demanda de productos.

La conclusión de este planteo, no sólo válido para la pauta oficial sino para todo el debate sobre la relación entre dinero privado y recursos privados, es que en un sistema económico, todo el dinero es de todos, no sólo los ingresos públicos. Tanto el dinero que recauda el Estado como el que recaudan las empresas privadas, pertenecen al sistema económico en su conjunto. La riqueza es generada por el trabajo del Pueblo. Sería como decir que el dinero depositado en los bancos es de los bancos. Eso sería otra trampa cultural.

O sería como decir que el espectro por donde se trasmiten las señales audiovisuales no es parte del espacio público sino que es de las empresas: no. Es espacio público y el Estado, como legítimo administrador de lo público, lo concesiona. Sin embargo, el negocio lo hacen los privados, y no el pueblo que es su verdadero propietario. $Y$ con ese dinero, financian su propio salto tecnológico, lo que contribuye al monopolio de la comunicación, y no a su democratización. Otra trampa cultural.

El espacio aéreo es público. La riqueza de nuestro subsuelo también. El Estado, una vez más como legítimo administrador de lo público, concesiona su uso bajo ciertas reglas. Pero de hecho, quienes se enriquecen son los grandes capitales que pueden invertir en ellos, y no el Pueblo que es su verdadero propietario. Trampa cultural.

Algo similar ocurre con la fertilidad de nuestro suelo: es propiedad pública. Sin embargo, el negocio de la fecundidad extraordinaria de nuestras tierras lo hacen los grandes grupos económicos. Otra trampa cultural. 


\section{Conclusión. La necesidad de un profundo debate conceptual e institucional. EI desafío de trasponer los límites estructurales impuestos por el neoliberalismo}

En definitiva, de lo que se trata es de invertir las proporciones de apropiación de la tasa de ganancia de los bienes públicos. De este modo, se incrementarían sustancialmente los fondos para que el Estado cumpla cabalmente con sus funciones, y entre ellas, la de financiar de modo pertinente a la política independiente, de modo de situarla en un lugar de suficiente poder de interpelación a los poderes fácticos. Y esto despejaría casi completamente el dilema de recurrir legalmente y a cielo abierto a los fondos necesarios para financiar la actividad política independiente. De este modo se iría equilibrando la relación de fuerzas entre política independiente -entendiendo a ésta como la que nos convoca en función de un modelo de sociedad, y no de la defensa de intereses particulares- y los poderes fácticos.

Pero además, el mayor excedente estatal no sólo serviría para financiar la política, sino también, por ejemplo, la inversión en investigación y desarrollo, de modo de reducir nuestra dependencia respecto de las patentes y derechos intelectuales en manos de los grandes laboratorios. Con esto abarataríamos el costo de productos esenciales para la población, y a través de este tipo de resultados concretos, aumentaríamos la legitimidad de las políticas públicas.

Todo esto conlleva, indudablemente, a un debate social en el plano de lo que llamamos batalla cultural. Y a un debate social sobre los cambios necesarios en el sistema institucional. Si, por ejemplo, la fuente última de la legitimidad del poder político es la voluntad del Pueblo, no puede ser que un estatuto la limite. Los límites a la continuidad de un proceso político los debe poner el Pueblo y no un estatuto.

Estas y otras cuestiones deberían ser materia de un profundo debate constitucional, no entendido como mera reforma en la redacción de nuestros estatutos normativos fundamentales, 
sino como oportunidad de masificar el debate sobre derechos, plantarlo en cada esquina y en cada rincón del país.

Desde luego que se trata de un arduo y trabajoso debate, pero debemos y merecemos afrontar el desafío, por más difícil que parezca. Luego de la experiencia vivida durante los gobiernos populares latinoamericanos de la primera década del siglo XXI, seguida del presente retroceso, está comprobado que el pos-neoliberalismo tropieza con límites estructurales, que, de no trasponerse, tornarían prácticamente inviable una segunda etapa. Es decir, debemos trasponerlos. Ello implica intervenir, desde una renovada legitimidad popular, sobre ciertas estructuras del poder real que no fueron modificadas. No sólo estructuras materiales, sino también simbólicas. Todo cambio de paradigma es destituyente en su naturaleza, por cuanto debe desmontar no sólo los dispositivos de poder concreto, sino toda la cultura fundante de la legitimidad anterior.

Y en esta restauración conservadora que ha embestido contra nuestros gobiernos populares en el continente, vale la metáfora de la piedra que rompe el cristal. La tarea militante no debe centrarse en seguir analizando la dureza de la piedra, ya que la cuestión del poder real no es un fenómeno natural sino político, y está harto-analizado por nosotros. En lo que debemos trabajar es en garantizar la solidez del cristal, es decir, del proyecto que oponemos al poder real, de modo de destronarlo perdurable, $y$ no transitoriamente, de su hegemonía. 